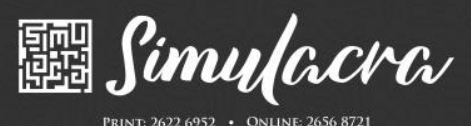 \\ PRINT: 26226952 - ONUNE: 26568721
}

\section{Statement of Author/s}

\section{Article Title:}

Political party elite and election-related violence in Nigeria: The nexus and implications for democracy and governance

\section{Author/s:}

Ahmed Olawale Moliki

The author/s whose names are listed above certify that:

1. We have NO affiliations with or involvement in any organization or entity with any financial interest, or non-financial interest in the subject matter or materials discussed in this article.

2. We declare on the responsibility that the submitted article is original, has not been published anywhere or has not been submitted to other journals.

3. We give permission and right to the journal editors to make some adjustment and publish this article in Simulacra.

4. We are willing to accept sanctions in any case if this statement is proved false.

20 May 2021

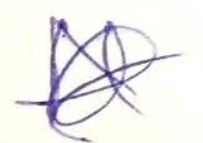

Ahmed Olawale Moliki

(First Author)

*Please sign in and upload the scanned document into the Simulacra's

"Supplementary Files" section. Thank you. 